\title{
Diurnal variations in the concentrations of volatile fatty acids in the alimentary tracts of wild rabbits
}

\author{
BY SUSAN J. HENNING AND F. J. R. HIRD \\ Russell Grimwade School of Biochemistry, University of Melbourne, \\ Parkville, Victoria 3052 , Australia
}

(Received 26 November $1970-$ Accepted 15 Fune I971)

\begin{abstract}
I. Wild rabbits were caught during both phases of the excretory cycle and their gut contents were analysed for volatile fatty acids (VFA).

2. All rabbits were found to have high concentrations of VFA in the caecum and in the proximal colon. Acetic was the most abundant acid followed by n-butyric, then propionic.

3. VFA concentrations in the caccum and in the proximal colon of rabbits caught during the day and during the night were similar. Hard pellets from the distal colon and rectum of rabbits caught during the night had considerably less VFA than did the soft pellets from rabbits caught during the day.

4. Owing to the ingestion of soft faeces, the VFA content of stomach material was greater in rabbits caught during the day than in those caught at night.

5. The results are discussed in terms of the mechanism of the diurnal excretion pattern and the role of coprophagy in the rabbit.
\end{abstract}

The occurrence of high concentrations of volatile fatty acids (VFA) in the fermentative organs of herbivorous animals is well known. These compounds represent major end-products from the microbial digestion of cellulose and other dietary constituents. For ruminants there is evidence that VFA are absorbed from the reticulo-rumen and omasum (Barcroft, McAnally \& Phillipson, I943-4; Gray, I947; Annison, Hill \& Lewis, I957) and are utilized by the host (Annison \& Lindsay, r96r; Leng, Steel \& Luick, 1967; Bull, Reid \& Johnson, 1970). In herbivores having fermentation in the hind-gut there is only scanty evidence for absorption and utilization of VFA. For the horse the high concentrations of VFA in the caecum and colon are paralleled by high concentrations in the blood draining these organs (Barcroft et al. 1943-4) and the situation is similar in the domestic rabbit (Cools \& Jeunjaux, I96r). Moreover, Elsden, Hitchcock, Marshall \& Phillipson (r945-6) measured the concentrations of VFA in various regions of the hind-gut of these animals and found that they were considerably lower in the regions close to the rectum than in the caecum, an observation consistent with absorption from the contents as they pass down the colon.

For the rabbit, the situation is complicated by the occurrence of a diurnal excretion pattern of two types of faeces. The two types are generally described as 'hard faeces' and 'soft faeces'. They differ in composition, the latter being relatively richer in water, protein, vitamins and bacteria. The animal normally re-cycles all of its soft faeces by ingestion direct from the anus. In wild rabbits soft faeces are excreted during the day and hard faeces during the night, whereas in the domestic rabbit the phasing is reversed.

The aim of the investigation now reported was to determine VFA concentrations in the gut contents of wild rabbits in their natural habitat and in particular to compare the VFA concentrations in the two phases of excretion. 


\section{MATERIALS AND METHODS \\ Collection of gut contents}

The wild rabbits (Oryctolagus cuniculus) were caught in partly cleared, stony country normally used for rough grazing of sheep. At the time of collection (February 1969) the only green plants to be seen were mosses and lichens, the pasture being dry.

Six rabbits were caught or shot between 20.30 and 23.00 hours with the aid of a spot-light. 'They are designated 'night rabbits'. Another six rabbits werc captured the following morning between 09.30 and $\mathrm{I} 1.30$ hours. These animals were dug out of their burrows. They are designated 'day rabbits'.

For all rabbits the gut contents were removed immediately after death, placed in sealed jars and frozen immediately in a dry-ice box. In each instance, contents were collected from five separate legions of the alimentary tract: (I) the upper (fundic) region of the stomach; (2) the lower (cardiac-pyloric) region of the stomach; (3) the caecum; (4) the proximal colon (down to the region where discrete pellets had begun to form); and (5) the distal colon plus rectum (from the end of region (4) to the anus).

In only two of the twelve animals was there sufficient material for analysis from the ileum.

On return to the laboratory, samples were stored at $-15^{\circ}$ until analysed.

\section{Determination of $V F A$}

The extraction of gut contents was as previously described for kangaroos and guinea-pigs (Henning \& Hird, I970), except that all samples were mixed with three volumes of water before the first centrifugation. Acidic stomach material was brought to neutrality before the extraction procedure. Total VFA were estimated by steam distillation and titration using a Radiometer $\mathrm{pH}$-stat and individual VFA were determined by gas-liquid chromatography (Henning \& Hird, I970).

\section{RESULTS}

\section{Observations on the gut contents}

All day rabbits had soft pellets in the rectum and identical unchewed pellets in the upper stomach; the lower stomach was filled with amorphous plant material. The night rabbits had hard pellets in the rectum. The upper stomach of most night rabbits also had intact soft pellets together with material that could be described as disintegrated soft pellets. Freshly eaten plant matter was confined to the lower stomach. These observations are in general agreement with those of Myers (I955).

\section{$V F A$ in gut contents}

Table I gives the water content and VFA concentrations in caecal material from the day and night rabbits. The differences between the mean values for the day and night animals were not significant. The values for total VFA given here are similar to those found for domestic rabbits (Elsden et al. 1945-6) and for guinea-pigs (Henning \& 
Hird, 1970). Acetic acid was present in the highest amounts, as is usual. However, the general pattern of molar proportions was different from that found in most other fermentative organs (Moir, 1968 ), the proportion of propionic acid being lower. Trace amounts of isobutyric, isovaleric and n-valeric acids were present in all samples. In two day rabbits, analysis of ileal contents gave total VFA values of ${ }_{15}$ and ${ }_{1} 7 \mu \mathrm{mol} / \mathrm{g}$ fresh contents.

Table I. Water and volatile fatty acids (umol) in caecal contents from wild rabbits caught during the night and during the day

(Mean values for six animals expressed per $g$ fresh contents)

\begin{tabular}{|c|c|c|c|c|}
\hline & \multicolumn{2}{|c|}{ Night } & \multicolumn{2}{|c|}{ Day } \\
\hline & Mean & $\mathrm{SE}$ & Mean & $\mathrm{SE}$ \\
\hline Water (g) & 0.77 & 0.01 & 0.76 & 0.01 \\
\hline Total VFA & 72 & 5.4 & 87 & $5 \cdot I$ \\
\hline Acetic acid & $6 I$ & 4.0 & 69 & $3 \cdot 7$ \\
\hline Propionic acid & $2 \cdot 3$ & 0.5 & 3.7 & 0.2 \\
\hline n-Butyric acid & $8 \cdot 3$ & 0.7 & 10.8 & $\mathrm{I} \cdot 5$ \\
\hline
\end{tabular}

None of the night means is significantly different from the corresponding day mean.

Table 2. Total volatile fatty acids ( $\mu$ mollg dry weight of contents) in contents from various regions of the gut of individual wild rabbits caught during the day and during the night

\begin{tabular}{|c|c|c|c|c|c|c|c|c|c|c|}
\hline \multicolumn{10}{|c|}{ Night } & \\
\hline Rabbit no. & $\ldots$ & $\mathrm{I}$ & 2 & 3 & 4 & 5 & 6 & Mean & SE & \\
\hline Caecum & & 293 & 288 & 412 & 228 & 362 & $32 \mathrm{I}$ & 317 & $25 \cdot 0$ & \\
\hline Proximal colon & & I38 & 105 & 332 & $25^{8}$ & 286 & 238 & 226 & 29.0 & \\
\hline Rectum & & - & 27 & 40 & 34 & 60 & 53 & 43 & $6 \cdot I$ & \\
\hline \multicolumn{10}{|c|}{ Day } & \\
\hline Rabbit no. & ... & 7 & 8 & 9 & 10 & II & 12 & Mean & $\mathrm{SE}$ & \\
\hline Caecum & & 249 & 408 & 340 & 349 & 456 & 407 & $3^{68}$ & $29 \cdot 6$ & NS \\
\hline Proximal colon & & 228 & 310 & 294 & 183 & 489 & 244 & 291 & $39 \cdot 1$ & NS \\
\hline Rectum & & 220 & 224 & 254 & $I 72$ & 292 & 203 & 228 & 16.9 & $*$ \\
\hline
\end{tabular}

Comparisons between day and night means are: NS, not significantly different; * significantly different, $P<0.005$.

Table 3. Relative amounts of water and volatile fatty acids (VFA) in the contents of the caecum, proximal colon and rectum of wild rabbits caught during the night and during the day

(VFA values were calculated on a dry-matter basis and are expressed as means for six animals)

\begin{tabular}{|c|c|c|c|c|c|c|}
\hline & \multicolumn{3}{|c|}{ Night } & \multicolumn{3}{|c|}{ Day } \\
\hline & Caccum & $\begin{array}{l}\text { Proximal } \\
\text { colon }\end{array}$ & Rectum & Caecum & $\begin{array}{l}\text { Proximal } \\
\text { colon }\end{array}$ & Rectum \\
\hline Water & 100 & 98 & 48 & 100 & $8_{3}$ & 73 \\
\hline Total VFA & 100 & 72 & I4 & 100 & 79 & 64 \\
\hline Acetic acid & 100 & 75 & I 2 & 100 & 79 & 70 \\
\hline Propionic acid & 100 & 68 & 13 & 100 & 66 & 46 \\
\hline n-Butyric acid & 100 & 39 & 3 & 100 & 72 & 27 \\
\hline
\end{tabular}


Since the passage of digesta through the colon is accompanied by the absorption of water, the comparison of VFA in the proximal colon and rectum is best made on a dry-weight basis. The values for total VFA in the three regions of the lower gut are given in Table 2. Again there was no significant difference in the concentrations in the caecum and proximal colon of night rabbits as compared with day rabbits. In contrast, the mean VFA concentration in the material from the rectum was significantly lower at night time than during the day $(P<0.005)$. That is to say, hard faeces contained small amounts of VFA whereas soft faeces contained a great deal. If rectal concentrations of VFA are compared with caecal concentrations it can be calculated that an average of $86 \%$ of the total amount disappeared during the formation of hard pellets compared with only $36 \%$ during the formation of soft ones (Table 3 ).

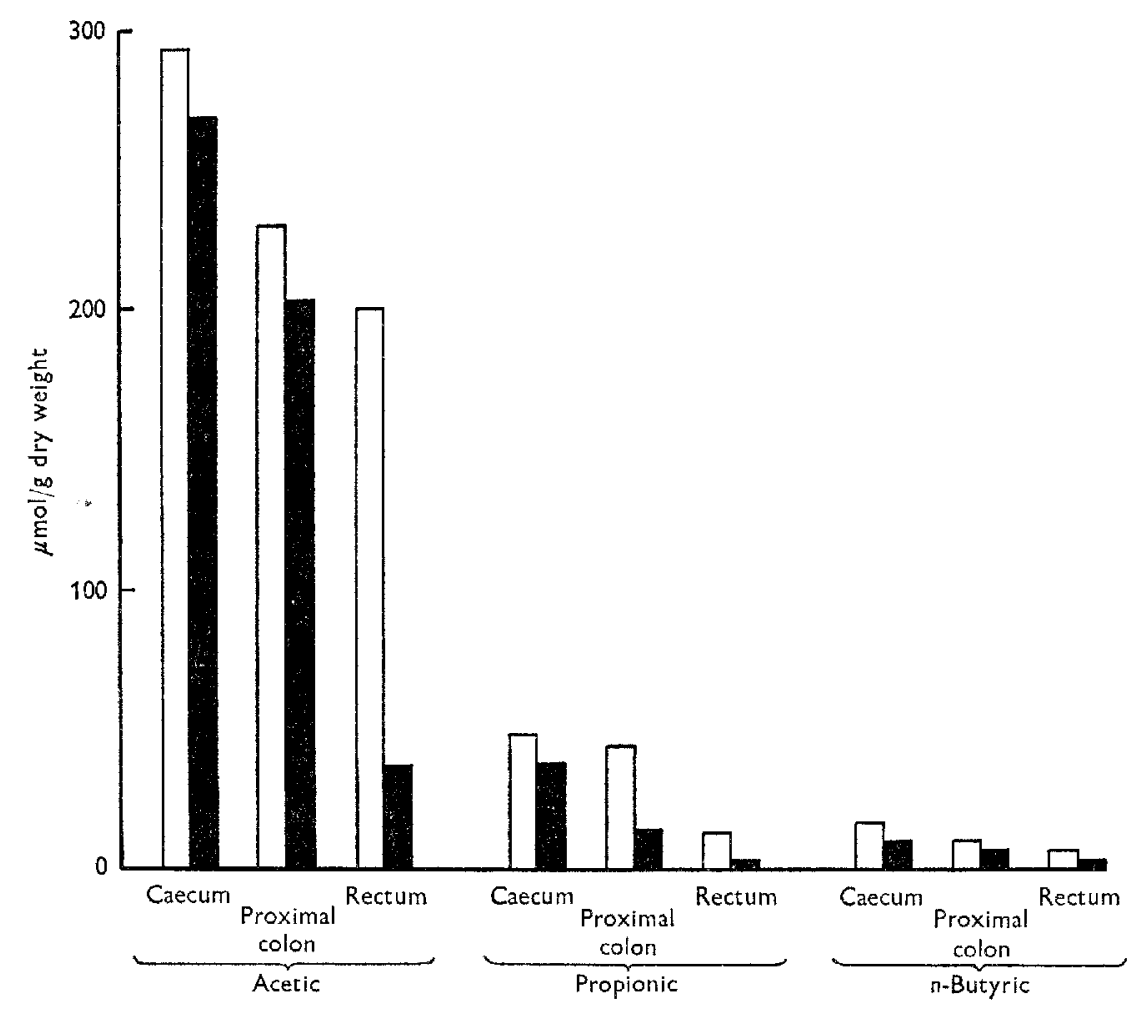

Fig. I. Mean concentrations of volatile fatty acids in contents from three regions of the large intestine of six rabbits caught during the night (圆) and of six rabbits caught during the day ( $\square$ ).

The relative molar proportions of the individual VFA were not the same in all three regions of the hind-gut. In both night and day rabbits, proportionately more butyrate than acetate and propionate disappeared during the passage through the colon (Table 3). The percentage decrease in each VFA was much greater than that for the water content of the same material, which suggests separate mechanisms for the disappearance of VFA and water.

The actual concentrations of VFA in different parts of the large intestine are shown 
in Fig. I. In order to collect sufficient material for analysis, it was necessary to combine the contents from approximately $30 \mathrm{~cm}$ lengths of the hind-gut to give proximal colonic and rectal material. For the proximal colon in particular there is probably a considerable gradient in VFA concentrations between its caecal and distal ends. Hence the heights of the bars in Fig. I give only a rough idea of the true concentrations of VFA at various regions of the colon.

Table 4. Volatile fatty acids in stomach contents from wild rabbits caught during the night and during the day

(Mean values for six animals expressed as $\mu \mathrm{mol} / \mathrm{g}$ dry weight of contents)

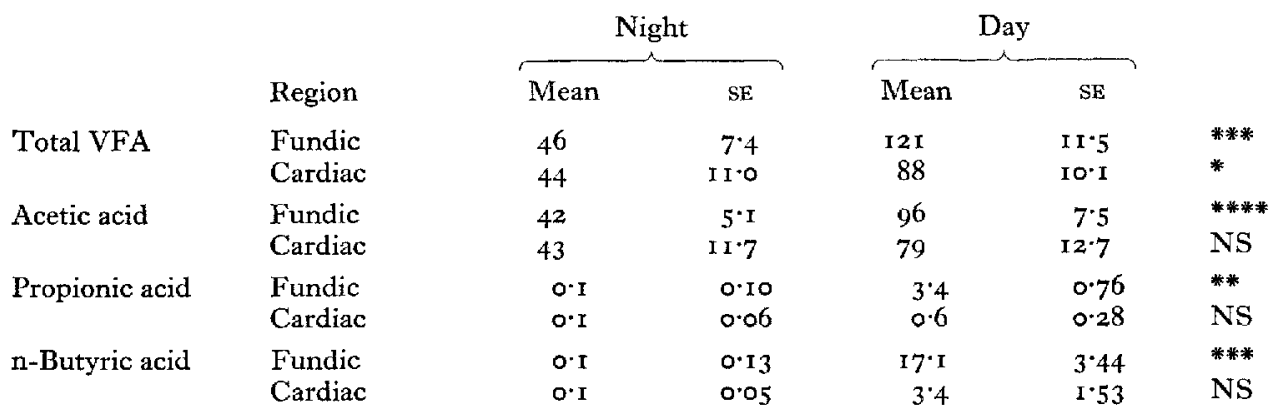

Values for the corresponding means of rabbits caught during the day and during the night are: NS, not significantly different; significantly different, * $P<0.025$, ** $P<0.010$, *** $P<0.005$, **** $P<0.001$,

Of the three major VFA, acetate was the one that disappeared in greatest amount from the digesta as they moved down the colon. This was particularly so during the formation of hard faeces. The mean water content of caecal material was $3.3 \mathrm{~g} / \mathrm{g}$ dry weight compared with $2.4 \mathrm{~g} / \mathrm{g}$ dry weight for soft faeces and $\mathrm{x} \cdot 6 \mathrm{~g} / \mathrm{g}$ dry weight for hard faeces.

The results of analyses of stomach material are given in Table 4. In the day rabbits, where stomach pellets were still intact, the VFA concentrations in the fundic material reflected those of the rectal material. The smaller amounts of VFA in the stomach material of the night rabbits were probably due to absorption, movement down the gut, or dilution by ingested plant matter.

\section{DISCUSSION}

The results presented are consistent with the generalization that all fermentative organs contain high concentrations of VFA, particularly acetic acid. The small amount of propionate in the caecal contents of the rabbits studied here was probably determined by the composition of the food residues entering the caecum (e.g. their low starch content). Low propionate concentrations are not a general characteristic of post-gastric fermentative organs, since propionate is not low in caecal contents from guinea-pigs (Henning \& Hird, 1970), horses (Alexander, 1952) and pigs (Friend, Cunningham \& Nicholson, 1963$)$.

The marked difference in the VFA content of the digesta from the caecal end of 
the colon and from the rectum, particularly during the excretion of hard faeces, implies extensive absorption by the colon. Water is also absorbed as digesta move towards the rectum. If caecal material is taken as a reference, our results suggest that there are separate mechanisms for the absorption of water and VFA by the colon of the wild rabbit. In functional terms there is an analogy between the colon of the rabbit and the omasum of the ruminant, since it is known that, in the sheep, the omasum absorbs large amounts of both water and VFA (Gray, Pilgrim \& Weller, I954).

\section{Table 5. Composition of hard and soft faeces of domestic rabbits during the day and during the night}

\begin{tabular}{|c|c|c|c|c|c|}
\hline Constituent & Units & Hard faeces & Soft faeces & $\begin{array}{c}\text { Caecal } \\
\text { contents }\end{array}$ & Reference \\
\hline $\begin{array}{l}\text { Protein } \\
\text { Fat } \\
\text { Crude fibre } \\
\text { Ash }\end{array}$ & $\begin{array}{l}\mathrm{g} / \mathrm{I} 00 \mathrm{~g} \text { dry } \\
\text { matter }\end{array}$ & $\begin{array}{r}\mathrm{I} 4.8 \\
\mathrm{I} \cdot 8 \\
27.8 \\
\mathrm{I} 4.8\end{array}$ & $\begin{array}{r}37 \cdot 8 \\
1 \cdot 5 \\
14 \cdot 3 \\
14 \cdot 3\end{array}$ & $\begin{array}{r}36 \cdot 4 \\
\mathrm{r} \cdot 8 \\
\mathrm{r} 3 \cdot 4 \\
15 \cdot 4\end{array}$ & $\begin{array}{l}\text { Huang, Ulrich \& } \\
\text { McCay (I954) }\end{array}$ \\
\hline $\begin{array}{l}\text { Nicotinic acid } \\
\text { Riboflavin } \\
\text { Pantothenic acid } \\
\text { Cyanocobalamin }\end{array}$ & $\begin{array}{c}\mu \mathrm{g} / \mathrm{g} \text { fresh } \\
\text { weight }\end{array}$ & $\begin{array}{c}39.7 \\
9.4 \\
8 \cdot 4 \\
0.89\end{array}$ & $\begin{array}{r}\mathrm{I} 39 \cdot \mathrm{I} \\
30 \cdot 2 \\
5 \mathrm{I} \cdot 6 \\
2 \cdot 92\end{array}$ & - & $\begin{array}{c}\text { Kulwich, Struglia } \\
\& \text { Pearson (1953) }\end{array}$ \\
\hline Bacteria & $\begin{array}{l}\text { Total counts/g } \\
\text { dry matter }\end{array}$ & $3^{\circ} 0 \times 10^{11}$ & $14.0 \times 10^{11}$ & $14.5 \times 10^{11}$ & $\begin{array}{l}\text { Bonnafous \& } \\
\text { Raynaud (r968) }\end{array}$ \\
\hline
\end{tabular}

The VFA values presented here for rabbit gut contents have a bearing on the question of the origin of the two different types of faeces in the rabbit. Earlier workers noted the similarity between the composition of the soft pellets and of material from the caecum (Table 5 ) and proposed that the soft pellets were of caecal origin, whereas the hard pellets represented material which had bypassed the caecum (Eden, I940; Thacker \& Brandt, 1955). If this were true then the contents of the proximal colon during either phase of the excretion cycle would be expected to reflect the type of faeces being formed in the distal colon. In other words, for wild rabbits caught at night with hard pellets in the rectum, the composition of the material in the proximal colon would be expected to be more like that in the rectum than that in the caecum. However, in the present study this was not found to be so. The VFA content of material taken from the proximal colon was not significantly different in night rabbits and day rabbits and, moreover, it was always more like caecal material than rectal material. These results are consistent with those of Bonnafous \& Raynaud (1967), who measured the protein content of material from various regions of the colon of the domestic rabbit during the day and the night and found that the composition of digesta in the first region of the proximal colon was independent of the type of faeces being formed. It therefore seems likely that both types of faeces originate in the caecum and that the differences between them are brought about mainly by the proximal colon. With soft faeces there is little modification of the caecal material during transit through the colon, whereas when hard faeces are being formed substantial amounts of bacteria, protein and vitamins as well as of VFA must be removed (Table 5). In this connexion, the proximal colon of the domestic rabbit has been shown, both in vivo and in vitro 
to have bacteriolytic activity that is sufficient to account for the difference between the bacterial counts of hard pellets and those of caecal material (Bonnafous \& Raynaud, I968). The products of this lytic reaction have not yet been defined. These observations, as well as those presented in the present paper, are consistent with the colon of the rabbit functioning as a second small intestine in series.

The control mechanism determining the diurnal modification of caecal contents during transit through the colon remains to be defined. One possibility is that the extent of modification depends on the rate of transit. Caecal contraction could force material through the proximal colon at a rate that limits absorption and other modifications and thus results in the formation of soft faeces. There is, however, one feature of soft pellets which is not consistent with this suggestion, namely that each pellet is enveloped by a discrete coat of mucoid material (Griffiths \& Davies, I963). The mucoid envelope begins to form just posterior to the sacculated region of the colon and could in itself prevent further modification of the digesta by providing a diffusion barrier.

In a herbivore with a post-gastric fermentative system, any mechanism which enables the host animal to digest and absorb the microbes and microbial products synthesized in the hind-gut must confer an advantage. Rumen micro-organisms are known to be a rich source of protein (Reed, Moir \& Underwood, 1949; Weller, I957; Hoogenraad $\&$ Hird, 1970) and of water-soluble vitamins (Hungate, 1966) and the same is probably true of caecal micro-organisms. Thus caecal material could provide an important dietary supplement, especially when food is scarce. In the rabbit it appears that two mechanisms have evolved for recovery of microbial proteins and vitamins. First there is the digestion and absorption which seems to operate in the colon during the formation of hard faeces (Bonnafous \& Raynaud, I 968) and secondly the process of reingestion of soft faeces. The relative contribution of the two mechanisms to the nutrition of the rabbit is not known, although in this connexion it is of interest that wild rabbits tend to spend a longer time in the soft faeces phase of the excretory cycle at those times of the year when food is scarce and grasses are dry (Myers, 1955).

The present work has shown that, in addition to proteins and vitamins, soft faeces are also rich in VFA. The extra VFA which the rabbit obtains by reingestion of its soft faeces probably represents only a small proportion of the total daily turn-over of VFA in the caecum. Hence, rather than conferring direct nutritional benefit, it is possible that the high concentrations of VFA in the soft pellets are important in enabling the animal to detect these pellets. It has been shown that germ-free rabbits excrete two types of faeces but do not consume the soft ones (Yoshida, Pleasants, Reddy \& Wostmann, I968), so it is certain that some bacterial component or metabolite is necessary to stimulate coprophagy. VFA, including the branched-chain acids, are possible candidates because of their strong odours.

We wish to acknowledge financial support from the Reserve Bank Rural Credits Development Fund and the Australian Research Grants Committee. We are grateful to Hird Brothers of Heathcote for considerable help in collecting animals. 


\section{REFERENCES}

Alexander, F. (1952). Q. fl exp. Physiol. 37, 205.

Annison, E. F., Hill, K. J. \& Lewis, D. (1957). Biochem. F. 66, 592.

Annison, E. F. \& Lindsay, D. B. (1961). Biochem. $7.78,777$.

Barcroft, J., McAnally, R. A. \& Phillipson, A. T. (1943-4). F. exp. Biol. 20, 120.

Bonnafous, R. \& Raynaud, P. (I967). Archs Sci. Physiol. 21, 26r.

Bonnafous, R. \& Raynaud, P. (I 968). Archs Sci. Physiol. 22, 57.

Bull, L. S., Reid, J. T. \& Johnson, D. E. (1970). F. Nutr. 100, 262.

Cools, A. \& Jeuniaux, C. (196I). Archs int. Physiol. Biochim. 69, I.

Eden, A. (1940). Nature, Lond. 145, 628.

Elsden, S. R., Hitchcock, M. W. S., Marshall, R. A. \& Phillipson, A. T. (1945-6). F. exp. Biol. 22, 19т. Friend, D. W., Cunningham, H. M. \& Nicholson, J. W. G. (1963). Can. F. Anim. Sci. 43, I56. Gray, F. V. (1947). J. exp. Biol. 24, I.

Gray, F. V., Pilgrim, A. F. \& Weller, R. A. (1954). F. exp. Biol. 31, 49.

Griffiths, M. \& Davies, D. (I963). F. Nutr. 80, I7I.

Henning, S. J. \& Hird, F. J. R. (1970). Br. F. Nutr. 24, I45.

Hoogenraad, N. J. \& Hird, F. J. R. (1970). Br. F. Nutr. 24, I19.

Huang, T. C., Ulrich, H. E. \& McCay, C. M. (1954). F. Nutr. 54, 62 I.

Hungate, R. E. (1966). The Rumen and Its Microbes Ch. 8, p. 33 r. New York: Academic Press.

Kulwich, R., Struglia, L. \& Pearson, P. B. (1953). \%. Nutr. 49, 639.

Leng, R. A., Steel, J. W. \& Luick, J. R. (1967). Biochem. F. 103, 785 .

Moir, R. J. (1968). In Handbook of Physiology Sect. 6, Vol. 5, p. 2673 [W. Heidel, editor]. Baltimore: Waverly Press.

Myers, K. (1955). Aust. F. Zool. 3, 336.

Reed, F. M., Moir, R. J. \& Underwood, E. J. (1949). Aust. F. scient. Res. B2, 304.

Thacker, E. J. \& Brandt, C. S. (1955). F. Nutr. 55, 375 .

Weller, R. A. (1957). Aust. F. biol. Sci. 1o, $3^{84}$.

Yoshida, T., Pleasants, J. R., Reddy, B. S. \& Wostmann, B. S. (1968). Br. F. Nutr. 22, 723. 